\title{
Injuries to polo riders: a prospective evaluation
}

\author{
Matías Costa-Paz, Luis Aponte-Tinao, D Luis Muscolo
}

\begin{abstract}
Objective-To assess prospectively the incidence, nature, and severity of injuries to polo riders competing in the 1996 Argentine High Polo season.

Methods-Assessment, documentation, and provision of care for all injuries sustained during the 1996 season by one of the authors. Riders were also surveyed retrospectively for their previous polo injuries.

Results-34 riders took part in the study. Nine injuries were sustained prospectively and 55 injuries were reviewed retrospectively (64 total). The injuries were categorised as minor (10), moderate (13), and major (41). Twenty five $(39 \%)$ injuries occurred in the arms, $20(31 \%)$ in the legs, $12(19 \%)$ in the head, $3(5 \%)$ in the back, and $4(6 \%)$ in the face. A fracture occurred in $25(39 \%)$ injuries as most resulted from a fall from the horse. Additionally, facial lacerations occurred prospectively in five riders but did not result in missed play. An overall injury rate of $7.8 / 1000$ player-game hours was calculated.

Conclusions-Although many sports have injury rates much greater than $8 / 1000$ player-game hours, the severity of most injuries occurring in polo was classified as major, with fractures and facial lacerations common. The use of a helmet with a face protector is recommended to decrease injury to players. A doctor experienced in the management of serious trauma should be present at all polo matches.

(Br F Sports Med 1999;33:329-332)
\end{abstract}

Keywords: polo; horse riders; injury

Polo is one of the world's oldest equestrian sports and appeared in the Orient well over 2000 years ago. The modern game consists of two teams composed of four mounted riders whose objective is to strike an $8 \mathrm{~cm}$ wooden ball with a long handled mallet. Each team attempts to pass the ball between two posts positioned at the ends of the playing field in order to score a goal. The game is divided into periods called "chukkers" of seven minutes each, and is composed of 6-8 chukkers, with the team scoring the most goals being the winner. Substitutions of riders are permitted only in the event of injury. ${ }^{12}$

Polo, a worldwide sport, was introduced into Argentina in 1875 by the British. Currently, there are over 250 polo clubs and about 3000 ranked polo players in Argentina, with additional non-ranked players. Each year Argentina's triple crown is held among the highest ranked players (High Polo season) and includes the Argentine Open, Tortugas, and Hurlingham Championships.

This study aimed at evaluating the incidence, nature, and severity of injuries to elite polo riders. Previous reports on injuries from equestrian sports did not consider polo riders specifically. This information should contribute to increasing the safety of the sport and enable the medical community to provide appropriate levels of care.

\section{Methods}

During the 1996 Argentine High polo season 34 elite players agreed to participate in the study and were followed up prospectively. One of the authors (LAT), a certified orthopaedic surgeon, attended all the games and provided care to the participants. Retrospective information on injuries sustained during the past five years was also obtained from each of the study participants by a questionnaire.

Polo riders are ranked by skill level (handicap) from -2 to 10 , with 10 denoting the highest proficiency. Players in this study had an average handicap of 8.5 (range 7-10), with 13 participants ranked at 10 . The participants' average age was 27 (range 21-42) years and all players were male.

Injury for this study was defined as any medical episode occurring during practice or match play which caused the rider to miss the following game or practice. Injuries were considered to be either traumatic or due to overuse and were classified as minor (absence from practice $<7$ days), moderate (absence from practice 7-30 days), or major (absence from practice $>30$ days). Conditions that did not result in time lost from competition (for example, contusions, simple sprains, or strains) were not considered as injuries. Facial lacerations, which are common in polo and might not cause a rider to miss a game, were recorded separately from the other injury figures.

Each participant played in an average of seven competition games and 30 practice games over the 10 week study, with actual playing time averaging 34.5 hours per rider.

\section{Results}

During the prospective study period, nine injuries occurred (table 1) - an incidence of $7.8 / 1000$ players per game hours.

From the retrospective survey, players reported an additional 55 injuries. Only seven players $(21 \%)$ reported no injuries during the past five years.

All injuries were combined for analysis (prospective and survey), resulting in a total of 64 . Most injuries were traumatic (40/64 (62\%)) and the rest were considered to be secondary 
Table 1 Specific moderate and major injuries occurring during three major league polo championships, prospective study $(n=9)$

\begin{tabular}{lll}
\hline Diagnosis & $\begin{array}{l}\text { Moderate } \\
\text { injury }\end{array}$ & $\begin{array}{l}\text { Major } \\
\text { injury }\end{array}$ \\
\hline $\begin{array}{l}\text { Head concussion } \\
\text { Dislocation of acromioclavicular joint }\end{array}$ & 1 & 3 \\
$\begin{array}{l}\text { Dislocation glenohumeral joint } \\
\text { Partial supraspinatus tendon tear }\end{array}$ & 1 & 1 \\
$\begin{array}{l}\text { Partial hip adductor tendon tear } \\
\text { Fracture of mandible }\end{array}$ & 1 & 1 \\
Total & 2 & 1 \\
\hline
\end{tabular}

Table 2 Specific minor, moderate, and major injuries registered retrospectively $(n=55)$

\begin{tabular}{lccc}
\hline Diagnosis & $\begin{array}{l}\text { Minor } \\
\text { injury }\end{array}$ & $\begin{array}{l}\text { Moderate } \\
\text { injury }\end{array}$ & $\begin{array}{l}\text { Major } \\
\text { injury }\end{array}$ \\
\hline $\begin{array}{l}\text { Fractures } \\
\quad \text { Hand-wrist }\end{array}$ & 1 & 6 \\
$\quad$ Humerus & & 1 \\
$\quad$ Clavicle-scapula & 1 & 4 \\
$\quad$ Foot & & 5 \\
$\quad$ Leg & & 1 \\
$\quad$ Patella & & 1 \\
$\quad$ Mandible & 1 & \\
$\quad$ Nose & 1 & \\
$\begin{array}{l}\text { Whumb ligament tear } \\
\text { Elbow sprain }\end{array}$ & 1 & \\
$\begin{array}{l}\text { Partial supraspinatus tendon tear } \\
\text { Partial hip adductor tendon tear }\end{array}$ & 1 & 1 & \\
$\begin{array}{l}\text { Posterior cruciate ligament tear } \\
\text { Knee sprain }\end{array}$ & 1 & 2 & 1 \\
$\begin{array}{l}\text { Medial meniscus tear } \\
\text { Ankle sprain }\end{array}$ & & & \\
$\begin{array}{l}\text { Eye complex traumatic lesion } \\
\text { Post-traumatic back pain }\end{array}$ & 2 & & 1 \\
$\begin{array}{l}\text { Head concussion } \\
\text { Total }\end{array}$ & & 2 & 1 \\
\hline & 10 & 11 & 94 \\
\hline
\end{tabular}

Table 3 Types of total injuries $(n=64)$

\begin{tabular}{lc}
\hline Injury & No (\%) \\
\hline Fracture & $25(39)$ \\
Sprain/strain & $12(19)$ \\
Head concussion & $12(19)$ \\
Muscular injury & $8(13)$ \\
Dislocation & $3(5)$ \\
Post-traumatic back pain & $3(5)$ \\
Complex lesion of eye & $1(2)$ \\
Facial laceration & 46 \\
\hline
\end{tabular}

due to overuse. According to severity, 10 were minor (16\%), 13 moderate $(20 \%)$, and 41 major (64\%) (tables 1 and 2). The most common injury type was fracture $(39 \%)$, followed by sprain (19\%), and concussion (19\%) (table 3). The location of injuries was 25 arms (39\%), 20 legs (31\%), 12 head (19\%), 4 face $(6 \%)$, and 3 back (5\%). The most common specific locations for injury were the head $(19 \%)$, shoulder $(17 \%)$, and hand-wrist $(17 \%)$ (table 4 ). The most common overuse injuries were hip adductor tendinitis and rotator cuff problems.

Twelve injuries (19\%) required surgery, seven of which were emergencies (five closed fractures, one open foot fracture, and one injury to the eye).

Facial lacerations, which did not cause absence from games, occurred in five participants prospectively and 41 times retrospectively (46 in total). The lacerations occurred in the periorbital region in $22(48 \%)$ cases and about the chin in $15(33 \%)$. Only two players used a face protector in the High Polo season
Table 4 Location and number of total injuries $(n=64)$

\begin{tabular}{lc}
\hline Location & No (\%) \\
\hline Head & $12(19)$ \\
Hand/wrist & $11(17)$ \\
Shoulder & $11(17)$ \\
Ankle-foot & $6(9)$ \\
Leg & $5(8)$ \\
Knee & $5(8)$ \\
Hip/thigh & $4(6)$ \\
Face & $4(6)$ \\
Back & $3(5)$ \\
Elbow & $3(5)$ \\
\hline
\end{tabular}

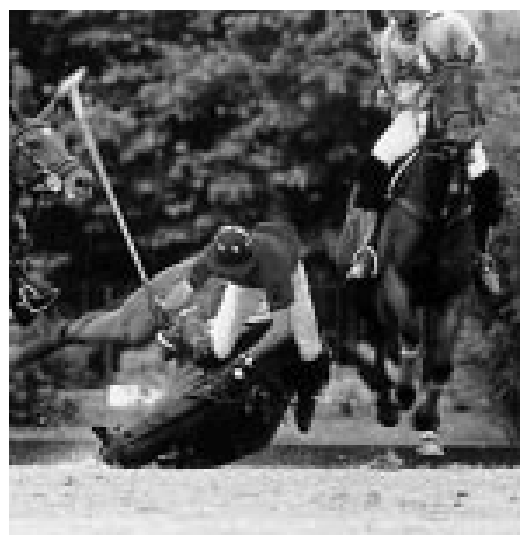

Figure 1 Player thrown forward and attempting to protect himself with outstretched arms, a mechanism that often causes lesions to the arm.

games, one of whom had previously been blinded in one eye owing to a polo injury.

\section{Discussion}

Polo is a demanding athletic activity which combines not only the skills of the rider but also the agility and performance of the horse. Significant forces are at play on the field as horses may weight up to $500 \mathrm{~kg}$ and gallop at speeds approaching $65 \mathrm{~km} / \mathrm{h}$. This energy is transmitted via the rider through the mallet into the ball. Injury can be caused by falls, equipment failures (saddles, stirrups), collisions, or impacts from mallets and balls. ${ }^{4}$

A computerised search of English publications failed to produce a previous report on the incidence of injuries in polo competition at any level. Although our study cohort is small and subject to significant variance compared with a larger group, our calculated incidence of injury of 7.8 per 1000 player-game hours represents an initial assessment from which further study may be made. It is interesting to note that compared with other sports, polo has a relatively low incidence of injury per 1000 player hours as ice hockey has $78.4,{ }^{6}$ rugby $44.9,{ }^{7}$ and soccer $16.9 .^{7}$ Although the incidence of injury is low, the severity of the injuries was quite high, with most injuries reported to be of major severity (41 (64\%)).

In our study injury was most commonly caused by a fall from the horse, which explains the high number of injuries to the arms, and head concussion (fig 1). Our findings are in agreement with other studies reporting horse riding sports injuries. ${ }^{8-14}$

The facial lacerations occurring during our study were largely preventable as helmets with face protection devices are available, yet as in 


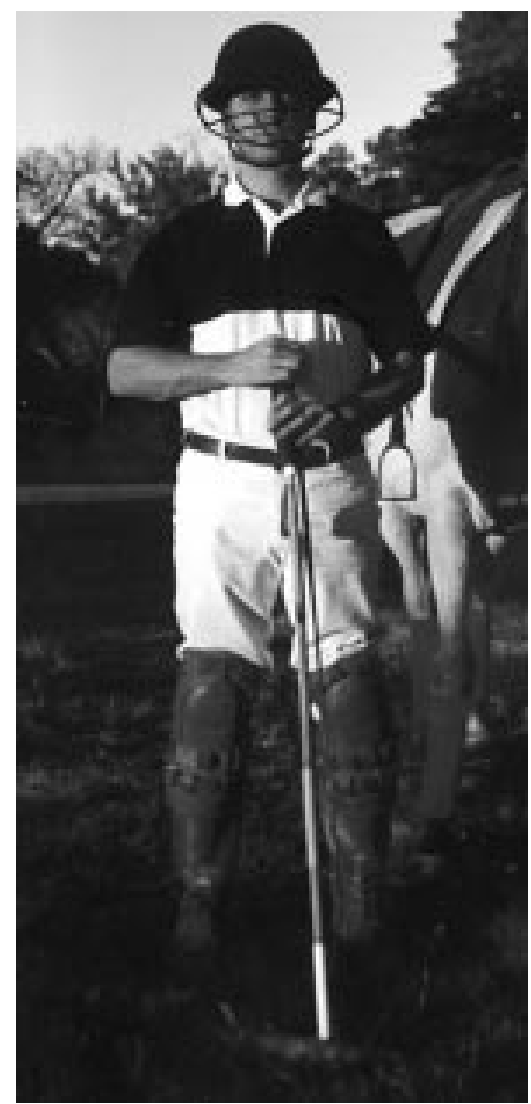

Figure 2 Player wearing polo hat with face guard and knee pads. Reproduced with permission.

ice hockey in past decades they are not used by elite level players. It is up to informed healthcare providers to educate polo players about the benefits of helmet and face protection (fig 2). ${ }^{15-17}$ It is significant that one of our participants had been blinded in one eye as a result of a polo accident.

\section{Conclusion}

Although the incidence of injury per playergame hour is lower than in many other sports, the proportion of serious injuries from polo competition reported in this study is high. Polo should be considered a sport where there is a high risk of serious injuries, and medical personnel trained in trauma care should be present at such competitions. We recommend that players should wear helmets with face guards attached in order to diminish the number and severity of injuries to the face and head.

We thank Ron Clark, for his assistance with the final preparation of the manuscript and Melito Cerezo for providing the photograph (fig 1).

\section{Contributors}

Matías Costa-Paz initiated and coordinated the formulation of the primary study hypothesis, discussed core ideas, designed the protocol - particularly the documentation of data, participated in data analysis, and writing the paper.

Luis Aponte-Tinao participated in the design and execution of Luis Aponte-Tinao participated in the design and execution of
the study-particularly data collection, data documentation, interpretation of the data, and contributed to the paper.

D Luis Muscolo discussed core ideas, interpretation of the findD Luis Muscolo discussed
ings, and edited the paper.

ings, and edited the paper.
All three authors take responsibility for the content of the paper.

1 Hobson R. Polo and ponies. London: JA Allen 1976:4-47.

2 MacGregor-Morris P. Equestrian sports and recreation. In: Edwards EH, ed. Encyclopedia of the horse. Avenel, New York: Crescent Books, 1991:134-7.

3 Bazan C, Bazan B. Argentina: polo y golf. Buenos Aires, Argentina: Editorial Delfos, 1994:141-50.

4 Gierup J, Larsson M, Lennquist S. Incidence and nature of horse riding injuries. A one year prospective study. Acta Chir Scand 1976;142:57-61.

5 Lester-Firth J. Equestrian. In: Fu FH, Stone DA, eds. Sports specific injuries. Baltimore: Williams and Wilkins, 1995: 315-31.

6 Lorentzon R, Wedren H, Pietila T. Incidence, nature, and causes of ice hockey injuries. Am f Sports Med 1988;16: 392-6.

7 Gibbs N. Injuries in professional rugby league. A three year prospective study of the South Sydney professional rugby league football club. Am 7 Sports Med 1993;21:696-700.

8 Griffin R, Peterson KD, Halseth JR, et al. Injuries in professional rodeo: an update. The Physician and Sports Medicine 1987;15:105-15.

9 Hammett DB. Injuries associated with horseback ridingUnited States, 1987 and 1988. FAMA 1990;264:18-19.

10 Meyers MC, Elledge JR, Sterling JC, et al. Injuries in intercollegiate rodeo athletes. Am F Sports Med 1990;18:87-91.

11 Hobbs GD, Yealy DM, Rivas J. Equestrian injuries: a five-year review. $\mathcal{F}$ Emerg Med 1994;12:143-5.

12 Grossman JA, Kulund DN, Miller, et al. Equestrian injuries. Results of a prospective study. $\mathscr{F} A M A$ 1978;240:1881-2.

13 Nelson DE, Bixby-Hammett D. Equestrian injuries in children and young adults. Am F Dis Child 1992;146:611-14.

14 O'Farrel DA, Irshad F, Thorns BS, et al. Major pelvic injuries in equestrian sports. Br 7 Sports Med 1997;31:249-51.

15 Hammett DB, Brooks WH. Common injuries in horseback riding. A review. Sports Med 1990;9:36-47.

16 Bond GR, Christoph RA, Rodgers BM. Pediatric equestrian injuries: assessing the impact of helmet use. Pediatrics injuries: assessing

17 Lloyd RG. Riding and other equestrian injuries: considerable severity. Br f Sports Med 1987;21:22-4.

\section{Take home message}

Polo should be considered a sport with a high risk of serious injury, and medical personnel trained in trauma care should be present at such competitions.

\section{Commentary}

The authors should be congratulated on being the first to document polo injuries. The results, however, may not be representative of all who play polo. The study period is small and is limited to professional players, but the anatomical pattern of injury is similar to that of other equestrian activities. Arm injuries are the most common and those to the head the most serious. The classification of injury is different from that of other studies in equestrian and non-equestrian sports, which makes the injury rate per hours played difficult to compare. Perhaps this journal could set criteria which researchers could follow, and thus more accurate comparisons of injury rates in all sports could be made. 
Helmets are worn in all polo competitions and the Hurlingham Club advises that one is worn to at least the European standard. It is, however, not mandatory. Three European manufacturers make polo helmets to the higher PAS 015 specification, with facial guards as an optional extra.

The number of people playing polo is small, but it is becoming more popular. It is now one of the activities organised by the Pony Club. In the past year there was at least one recorded death from a head injury at a Pony Club polo competition. The young look to their peers to set an example with high standards of safety, and this will have a greater effect on reducing injuries than mandatory rules.

MICHAEL WHITLOCK Barnet, Herts

\section{Injury time}

The standard of medical care for many team sports has improved enormously over the past $10-15$ years. Doctors and physiotherapists have sought out practical and theoretical training in the care of athletes. As a result, many now have diplomas or MScs in sport and exercise medicine.

In our most popular team sports, in particular association and rugby football, there is no facility within the rules of the game for a player to be replaced temporarily to allow these well trained medical staff time to perform an adequate evaluation of an injury. With the exception of a blood injury in rugby, these sports do not allow a replaced player to return to the field of play. This results in a rapid and inadequate assessment under pressure from the referee and coaches. The outcome may be that the over cautious doctor will withhold a player from the rest of the game unnecessarily, and the less cautious doctor may allow an unfit player to return, causing worsening of the injury or putting the player at risk of another injury.
There are arguments that the use of unlimited substitutions will change the nature of the game. This is a difficult argument to sustain as the number of players on the pitch remains unchanged and the skills required for success are the same. The only difference is that neither side will be exposing injured players (valuable assets) to further injury. The physical demands on players in terms of the intensity of competition and numbers of matches has never been greater. It is time to change the rules to allow players to be taken off the field for a full medical assessment and to be allowed to return to play if fit to do so. This will allow the medical team to practise good sports medicine. It will minimise the risk of further injury to an injured player, and it will not deprive a team and their supporters of a player who has a minor injury but was actually fit to continue the match.

PAUL D JACKSON

Sports physician and general practitioner,

St fames Surgery, Devizes, Wiltshire, United Kingdom 